\title{
Distúrbios comportamentais em ruminantes não associados a doenças: origem, significado e importância ${ }^{1}$
}

\author{
Pedro Malafaia ${ }^{2 *}$, José Diomedes Barbosa ${ }^{3}$, Carlos Hubinger Tokarnia ${ }^{2}$ \\ e Carlos Magno Chaves Oliveira ${ }^{3}$
}

\begin{abstract}
Malafaia P., Barbosa J.D., Tokarnia C.H. \& Oliveira C.M.C. 2011. [Behavioral disturbances in ruminants not associated with disease: Origin, significance and importance.] Distúrbios comportamentais em ruminantes não associados a doenças: origem, significado e importância. Pesquisa Veterinária Brasileira 31(9):781-790. Departamento de Nutrição Animal e Pastagem, Instituto de Zootecnia, Universidade Federal Rural do Rio de Janeiro, Seropédica, RJ 23890-00, Brazil. E-mail: malafaia_ufrrj@yahoo.com.br

The scientific study of animal behavior, especially when the animated or inanimated environment is changed, is the main objective of ethology. Many diseases which occur in ruminants develop some degree of change in their behavior. Professionals that work with ruminants should distinguish abnormal behavior due to environmental disturbance when their welfare is negatively affected (i.e. feedlots with high stock ratio, shade deficiencies in pastures, heat stress, and errors in nutritional management) from disease conditions or nutritional deficiencies (i.e. depraved appetite caused by sodium deficiency or by lack of physically effective fiber). The purpose of this paper is to discuss the main behavioral disturbances (i.e. abnormal herd behavior, stereotypies, cross-sucking, bar-biting) verified in ruminants raised under intensive or extensive conditions in Brazil.
\end{abstract}

INDEX TERMS: Animal welfare, ethology, ruminants, stereotypic behavior.

RESUMO.- 0 estudo científico do comportamento animal frente às distintas modificações do ambiente (inanimado ou não) onde os mesmos estão sendo criados, constitui o principal objetivo da etologia. Por outro lado, muitas doenças que acometem os ruminantes também cursam produzindo diversas alterações no comportamento desses animais; portanto, os profissionais que trabalham com ruminantes precisam reconhecer o que vem a ser um comportamento anormal, decorrente do empobrecimento ambiental associado ou não a erros alimentares e que resulta em prejuízos ao bem-estar dos animais (p.ex. confinamentos com superlotação, falta de sombra nas pastagens, volumosos finamente moídos) daqueles oriundos de doenças ou estados carenciais, como por exemplo a depravação do apetite causada pelas deficiências de sódio, cobalto e de fibra fisicamente efetiva. 0 propósito des-

\footnotetext{
${ }^{1}$ Recebido em 22 de junho de 2011.

Aceito para publicação em 5 de julho de 2011.

2 Departamento de Nutrição Animal e Pastagem, Instituto de Zootecnia, Universidade Federal Rural do Rio de Janeiro (UFRRJ), Seropédica, RJ 2389000, Brasil. *Autor para correspondência: malafaia_ufrrj@yahoo.com.br

${ }^{3}$ Central de Diagnóstico Veterinário, Faculdade de Medicina Veterinária, Universidade Federal do Pará (UFPA), Campus Castanhal, Rua Maximino Porpino da Silva 1000, Centro, Castanhal, PA 68740-080, Brasil.
}

sa revisão é discutir sobre os principais desvios comportamentais verificados nos ruminantes domésticos criados em sistemas intensivos ou não no Brasil.

TERMOS DE INDEXAÇÃO: Bem-estar, estereotipias, etologia, ruminantes.

\section{INTRODUÇÃo}

Em um sistema de produção de ruminantes, é de fundamental importância que os criadores e os técnicos que lidam com os animais conheçam muito bem o que vem a ser o comportamento normal das diferentes categorias com quem irão interagir. Para tal, faz-se necessário compreender como se dão às distintas interações dos animais no ambiente onde são criados, pois esse entendimento permitirá evitar situações negativas que podem resultar em estresse e prejuízos econômicos. 0 estresse é um efeito ambiental sobre o(s) indivíduo(s) e que impõe uma sobrecarga em seu sistema de controle (homeostase) e reduz sua capacidade de ajuste frente ao ambiente hostil (Broom \& Johnson, 1993).

De forma similar ao verificado em outras espécies não domesticadas e criadas em cativeiro pelo homem, os ruminantes também passam a exibir comportamentos incomuns em decorrência da presença de fatores que promovam 
estresse, principalmente quando associados a erros alimentares. Portanto, assim como os demais animais, os ruminantes exigem um conjunto de fatores ambientais que promovam o seu bem-estar e a falta ou a provisão deficiente de um ou mais dos recursos necessários ao bem-estar desses animais é que dará origem aos diversos transtornos comportamentais verificados neles. Segundo Fraser et al (1997) o bemestar animal pode ser caracterizado quando o desempenho dos animais for compatível com o propósito deles, quando se sentirem bem (p.ex. isentos de dores) e quando viverem em ambiente adequado.

Por outro lado, muitas doenças ou estados carenciais cursam com alterações comportamentais que precisam ser diferenciadas daquelas causadas pela deterioração do bem-estar dos animais. 0 objetivo da presente revisão é o de descrever sobre alguns distúrbios comportamentais que estão sendo observados com certa freqüência em ruminantes criados em sistemas intensivos ou não.

\section{COMPORTAMENTO SOCIAL E UTILIZAÇÃO DO ESPAÇO FÍSICO}

Como os bovinos são animais gregários, a competição pelos diversos recursos ambientais entre eles é uma constante diária. Do gregarismo originam-se interações agressivas entre animais de um mesmo grupo que, sob condições naturais, são controladas por mecanismos que definem padrões de organização social entre os indivíduos de um ou mais grupos. A definição do espaço individual bem como a distância de fuga possui importante papel no arranjo social do rebanho (Costa \& Costa e Silva 2007).

Existem dois padrões de ordem social dentro de um grupo de bovinos: a hierarquia de dominância e a liderança durante a movimentação. A primeira é fruto das interações agressivas entre os indivíduos de um mesmo grupo ao competirem por um dado recurso ambiental. Isso sugere precaução na formação dos lotes em sistemas intensivos de produção (confinamentos, free-stall, etc) sob risco de ser gerado um constante estado de estresse nos animais. Com relação à movimentação dos animais, sempre há um pequeno grupo que começa o deslocamento, sendo então seguido pelos demais; os animais desse grupo são os líderes, que necessariamente não são os animais mais agressivos nem os mais fortes; por exemplo, em fazendas de cria as vacas que iniciam o deslocamento e guiam o restante do rebanho são, via de regra, as mais velhas (Costa \& Costa e Silva 2007).

Erros frequentes devido ao desconhecimento da existência dos dois padrões de ordem social dos bovinos são praticados por ocasião da suplementação mineral (Peixoto et al. 2005), onde os fazendeiros usam cochos com 1 a $2 \mathrm{~cm}$ de espaço linear por animal (Ex. lotes de 100 ou mais animais suplementados em cocho de 1,5 m de comprimento). Outra situação errônea muito comum ocorre na suplementação protéico-energética, ao se utilizar cochos de tamanho inadequado ( $<5 \mathrm{~cm} /$ animal) (Malafaia et al. 2003). Nas duas situações, os animais líderes são os primeiros a chegarem nos cochos, consomem os produtos e quando se retiram, os demais animais (liderados) os seguem muitas vezes sem ingerirem os suplementos. Estima-se que cerca de 10 a $15 \%$ dos animais não ingerem suplementos minerais devido a ques- tões hierárquicas e de influência da liderança de movimentação (Peixoto et al. 2005). Esses erros podem resultar na deficiência mineral em uma fração do lote (no caso da suplementação mineral), na grande variação no ganho de peso por ocasião da suplementação protéico-energética realizada na época da estiagem ou no consumo excessivo de uréia quando presente nesses suplementos. Esse último aspecto foi verificado em uma propriedade onde a suplementação protéicoenergética foi interrompida por aproximadamente duas semanas e quando foi novamente reiniciada, morreram 10 das 40 novilhas que tiveram acesso e ingeriram avidamente 0 suplemento que continha uréia em sua composição (Tokarnia, dados não publicados 2007).

Na Figura 1 pode-se verificar o impacto que um ou dois cochos contendo um mesmo suplemento protéico-energético resultou no desempenho de dois grupos de bovinos, muito uniformes em peso e grau de sangue, pastando capim colonião (Panicum maximum cv. colonião) manejado sob lotação contínua e taxa de lotação fixa de 0,8 UA/ha na época de seca (Malafaia, dados não publicados 2007). Enquanto os animais que receberam o suplemento em dois cochos, distantes aproximadamente 30 metros um do outro, ganharam, em média, $103 \mathrm{~g} /$ dia e com menor variação individual entre eles $(\mathrm{dp}=$ $85 \mathrm{~g} / \mathrm{dia}$ ), os animais que tiveram o suplemento disposto em um cocho ganharam, em média, $68 \mathrm{~g} /$ dia e com grande dispersão dos valores entre os animais ( $\mathrm{dp}=142 \mathrm{~g} / \mathrm{dia})$. 0 consumo médio diário do suplemento foi de 101 e 93 g/cabeça/ dia para os grupos que tiveram acesso a um ou dois cochos, respectivamente.
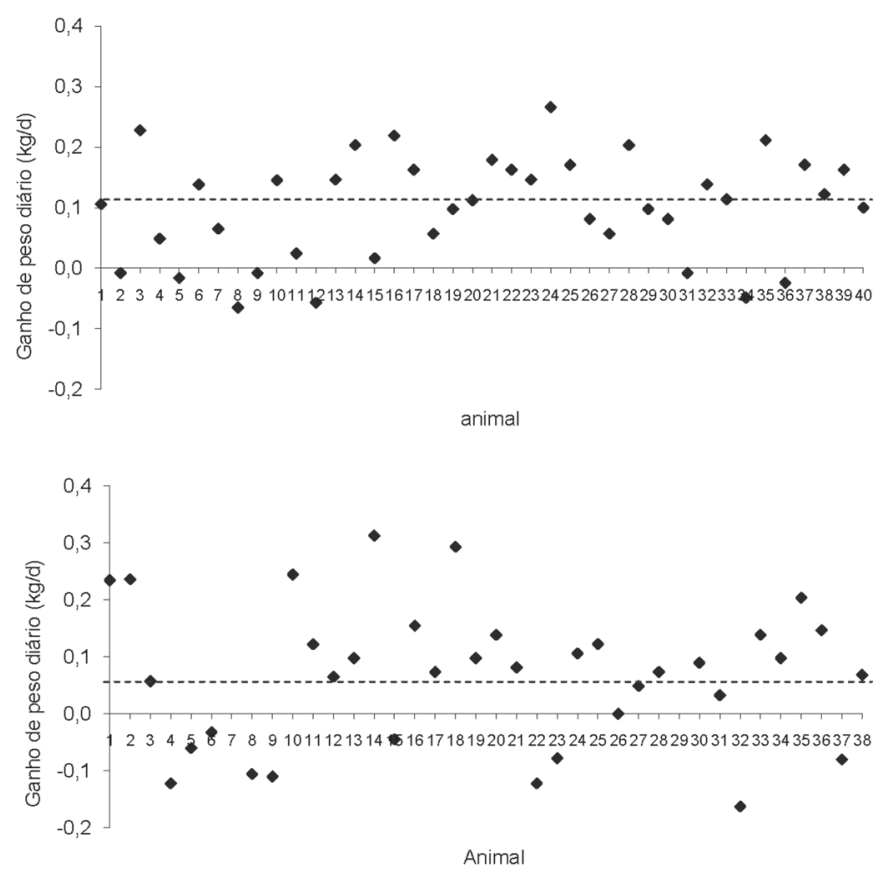

Fig.1. Ganho de peso diário de bovinos recebendo um mesmo suplemento protéico-energético. 0 gráfico superior refere-se aos animais que tiveram acesso a dois cochos, distantes aproximadamente 30 metros um do outro, e o gráfico inferior descreve o desempenho dos animais que tiveram o suplemento disponibilizado em apenas um cocho. As linhas horizontais pontilhadas referem-se às médias gerais dos ganhos diários de peso (Malafaia, dados não publicados, 2007). 
Se a formação de grupos for feita de acordo com o interesse humano, com o objetivo de facilitar o manejo diário, a organização social pode ser afetada. Por exemplo, bovinos em condições de alta concentração populacional não podem evitar a violação de seu espaço individual, o que pode resultar num aumento de agressividade e estresse (Schake \& Riggs 1970, Arave et al. 1974, Kondo et al. 1984). Quando os grupos são enormes os animais podem ter dificuldades em reconhecer cada companheiro e em memorizar suas posições na hierarquia social do rebanho, o que também aumenta a probabilidade de interações agressivas (Hurnik 1982). Como conseqüência, os animais mantidos em grupos com elevada lotação, têm redução do desempenho individual (Czako 1983) e desenvolvem distúrbios comportamentais (Syme \& Syme 1979), o que reflete a degradação das condições que levam ao bem-estar desses animais.

Não é conhecido nem definido qual o tamanho máximo ou ideal que um grupo de bovinos deva ter. É importante que o lote seja estável em sua composição, uma vez que qualquer alteração, sobretudo a entrada de novos animais, irá alterar a hierarquia social já definida e poderá gerar impactos negativos na produção e no bem-estar (Costa \& Costa e Silva 2007).

A maior variação no peso dentro do grupo também é um fator importante, pois o número de interações agonísticas é maior em grupos com grande discrepância nos pesos dos animais quando comparadas com lotes cuja variação no peso é menor (Hindhede et al. 1999). A dominância se dá pelas interações agressivas entre os animais do mesmo grupo ao disputarem por alimentos dispostos nos cochos, sobretudo quando o espaço disponível destes é limitado. Mesmo quando criados em pastagens, a oferta de suplementos alimentares aos bovinos sempre propicia disputas (Malafaia et al. 2003).

Também devem ser considerados o temperamento dos animais (agressivos ou não) e suas relações com os demais animais do grupo. Animais muito agressivos ou muito submissos devem ser retirados do lote, pois os primeiros interferem no consumo de alimentos e geram elevado grau de estresse nos demais e os últimos, apanham com freqüência, não se alimentam adequadamente ou são subjugados por comportamentos anormais, como a sodomia.

Não é raro, em fazendas de gado de corte, ver uma vaca multípara dominante e agressiva em seu próprio trabalho de parto expulsar outra vaca ou novilha recém parida tentando tirar-lhe a cria. Acontece que após apropriar-se do bezerro alheio e expulsar a outra fêmea, seu parto conclui-se e ela opta por um dos neonatos abandonando o outro. Tal comportamento não é incomum, principalmente em propriedades cuja estação de monta é curta, especialmente quando nulíparas e vacas compartilham o mesmo pasto maternidade. Neste caso a atenção do(s) responsável(veis) pelo cuidado com os recém-nascidos é fundamental para evitar o problema (Magnoli Costa 2011).

Uma vez definida a hierarquia social em um grupo a ordem é relativamente estável e as posições respeitadas; disputas e desavenças são raras e as categorias são mantidas com simples ameaças; os atritos aparecerão quando animais estranhos forem introduzidos no lote (Costa \& Costa e Silva 2007).

Atualmente, com base em estudos que comprovam que é possível obter melhores resultados no ganho de peso e na qua- lidade final da carcaça (Ítavo et al. 2008), alguns criadores têm optado por manter os animais não castrados nos confinamentos ou nas pastagens. Porém, lotes de animais inteiros pós-púberes, com grande variação de peso e submetidos à elevadas taxas de lotação, sobretudo em presença de outros fatores externos, como estresse térmico, espaço reduzido de sombra e excesso de lama, passam a exibir sodomia, que é um distúrbio comportamental que se caracteriza quando um animal é repetidamente montado por outro(s), maior(es) e mais forte(s), que acaba(m) por feri-lo ou até mesmo levá-lo a morte (Barbosa, comunicação pessoal 2010). A sodomia pode estar mais relacionada com o empobrecimento ambiental e com a degradação do bem-estar dos animais do que propriamente com o desejo sexual. Os animais dominantes, que saltam repetidamente sobre os outros, lesionam os cascos posteriores, pois a intensa pressão do peso sobre as unhas causa danos à microcirculação do casco, o que origina hematomas na sola, seguidos por ulcerações nas mesmas. Essas lesões podais interferem negativamente no consumo de alimentos, reduzem o ganho de peso, comprometem a saúde dos animais e geram despesas consideráveis com seu tratamento.

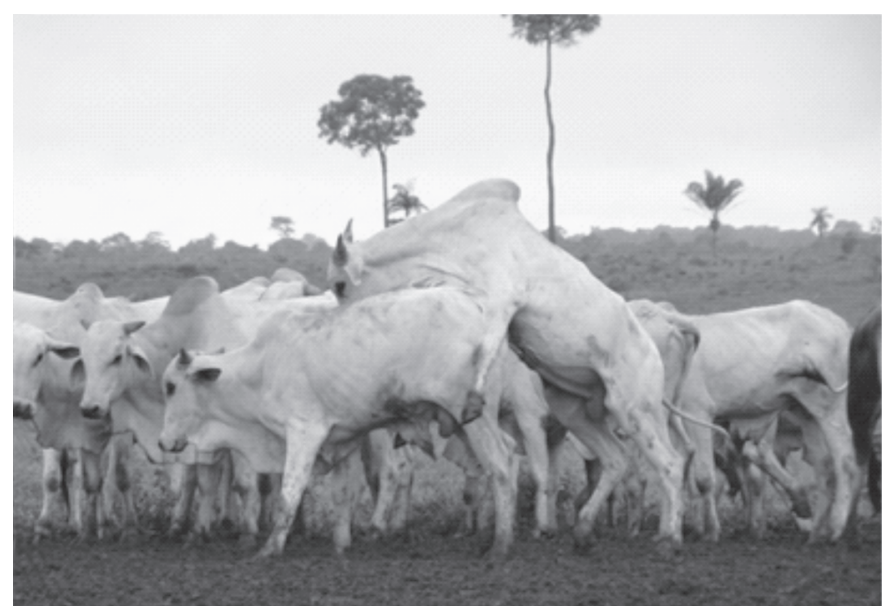

Fig.2. Animal criado em ambiente de pastagem e praticando sodomia.

No Estado do Pará, muitas pastagens foram formadas após intenso e indiscriminado desmatamento cuja resultante foi a degradação dos solos, a ausência de produtores naturais de sombra e a grande incidência de tocos e troncos, que atuam como obstáculos naturais à locomoção dos animais (Barbosa, comunicação pessoal 2010). Nessa região, caracterizada por intensa precipitação pluviométrica, é comum os animais permanecerem em pastos alagadiços ou bastante úmidos e terem que caminhar por quilômetros em estradas formadas por pedriscos (pizarra) para serem manejados em currais muitas das vezes inapropriados (Barbosa, comunicação pessoal 2010). A sodomia, originada pela manutenção de machos inteiros criados nas circunstâncias descritas acima, é um potencial agente traumatizante dos cascos dos bovinos.

\section{ALTERAÇÕES COMPORTAMENTAIS DEVIDO AO ESTRESSE TÉRMICO}

A provisão de conforto térmico aumenta a produtividade e as eficiências reprodutiva e de utilização de alimentos. Dentre 
os métodos de aperfeiçoamento ambiental podemos citar a manutenção e o posicionamento de produtores de sombras que, ao interceptarem os raios solares, podem reduzir a carga térmica radiante em $30 \%$ ou mais (Gangwar 1988). Dessa forma, em ambientes quentes e com alta incidência de radiação solar, deve-se prover sombra para os animais, o que reduzirá o aquecimento corporal e facilitará sua termorregulação (Stafford-Smith et al. 1985). A manutenção de um ambiente ventilado e sombreado reduz o dispêndio de energia a ser gasta com a termorregulação, o que permite dispor mais energia para as funções produtivas dos animais.

É fato conhecido que os animais procuram a sombra nas horas mais quentes do dia (Bennett et al. 1985). Como a exigência de sombra, descrita em $\mathrm{m}^{2} /$ animal ainda não é definida, torna-se difícil o estabelecimento de uma regra geral a respeito de quando e o quanto desse recurso deve ser ofertado; via de regra é recomendável que haja sombra capaz de atender as necessidades de todos os animais ao mesmo tempo à qualquer hora do dia. Bovinos mantidos em um ambiente com pouca área de sombra disponível sempre irão disputar pela área sombreada, sendo os mais velhos e fracos aqueles que ficarão sem o benefício desse valioso recurso ambiental.

Para minimizar a produção diária de calor, as vacas sob estresse térmico reduzem sua atividade física, aumentam a freqüência respiratória e reduzem a ingestão de alimentos em até $30 \%$. Há também uma significativa redução do tempo gasto ruminando, pois muito calor é produzido pela atividade muscular durante a ruminação. Há mudança no padrão alimentar caracterizada pela ingestão mais freqüente de pequenas quantidades de alimento, do aumento da escolha por concentrados em detrimento da forragem e da maior participação do consumo noturno, onde a temperatura ambiente é menor. A redução do tempo de ruminação associada à maior preferência por grãos e a perda de $\mathrm{CO}_{2}$ e/ou $\mathrm{HCO}_{3}{ }^{=}$em decorrência da intensa sialorréia e da taquipnéia, aumenta significativamente o risco de acidose ruminal e metabólica. A acidose ruminal e a redução do tempo de ruminação propiciam, respectivamente, um

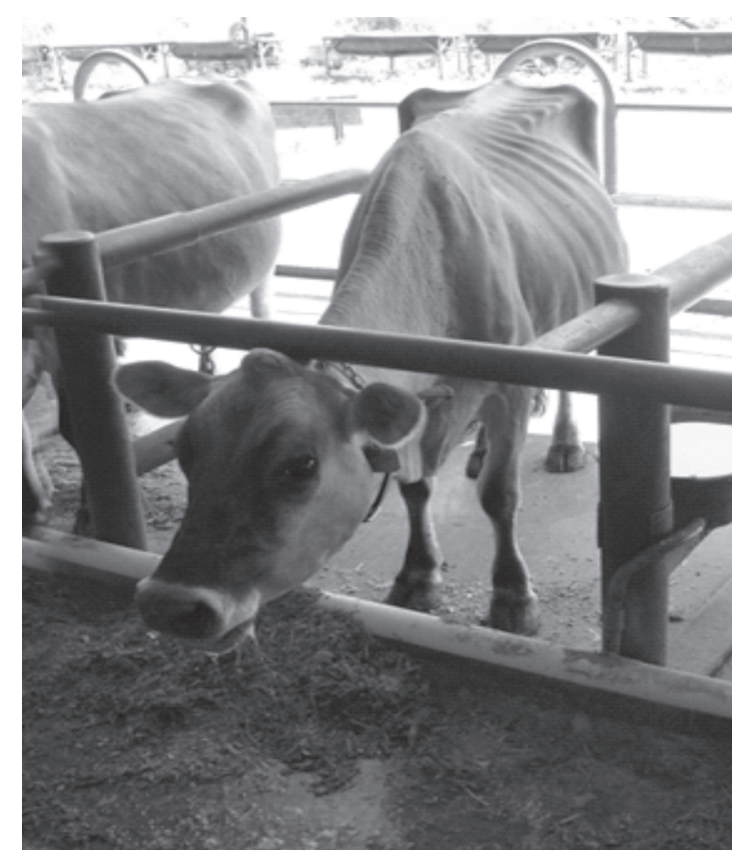
(n) decréscimo na digestibilidade da fibra devido a menor atividade das bactérias fibrolíticas ruminais e um maior escape ruminal de partículas fibrosas de grande tamanho e que irão aparecer nas fezes (Malafaia, comunicação pessoal 2010).

\section{ESTEREOTIPIAS}

Os ruminantes quando criados em sistemas intensivos, sobretudo se submetidos à presença constante de variáveis que agravam ou potencializam o estresse, podem desenvolver comportamentos estereotipados ou de auto-estimulação. As estereotipias são definidas como movimentos repetitivos, regulares, de mesma forma e, aparentemente, sem possuir nenhum propósito útil (Kiley-Worthington 1977). Para Sambraus (1985), as estereotipias possuem três características: o modelo produzido é morfologicamente idêntico, o comportamento deve ser repetido constantemente da mesma forma e a realização da atividade produzida não tem um objetivo determinado.

Nas situações onde algo obstrui o alcance de um dado objetivo, aparecem as "frustações" cujas origens podem ser interna e/ou externa ao(s) indivíduo(s); segundo Dantzer (1986) as "frustrações" são a principal força geradora das estereotipias nos seres vivos.

Os ruminantes domésticos são herbívoros que sofreram pressões de seleção no ecossistema das pastagens, onde viviam em um ambiente em condição de estresse reduzido e sem limitações ao seu bem-estar fisiológico durante o processo evolutivo/seletivo; esse aspecto refletiu na manutenção, ao longo do processo seletivo, do que Dantzer (1986) chama de máxima complexidade do ambiente natural onde não haveria restrições às sensações exteroceptivas. Porém, com a necessidade de se intensificar a produção de proteína animal para o consumo humano, os produtores alteraram significativamente o meio ambiente de criação dos ruminantes, no qual os animais passaram a ter que experimentar fontes externas potencialmente frustantes, tais como a retirada do ambiente natural das pastagens, a restrição da livre movimentação, a elevada densidade populacional, a imposição de ouvir, sentir, ver, cheirar e viver em presença de elementos criados pelo homem (como ordenhadeira, currais, trator, lama e agulhadas) e

Fig.3. Estresse térmico em vacas criadas em sistema tiestall.

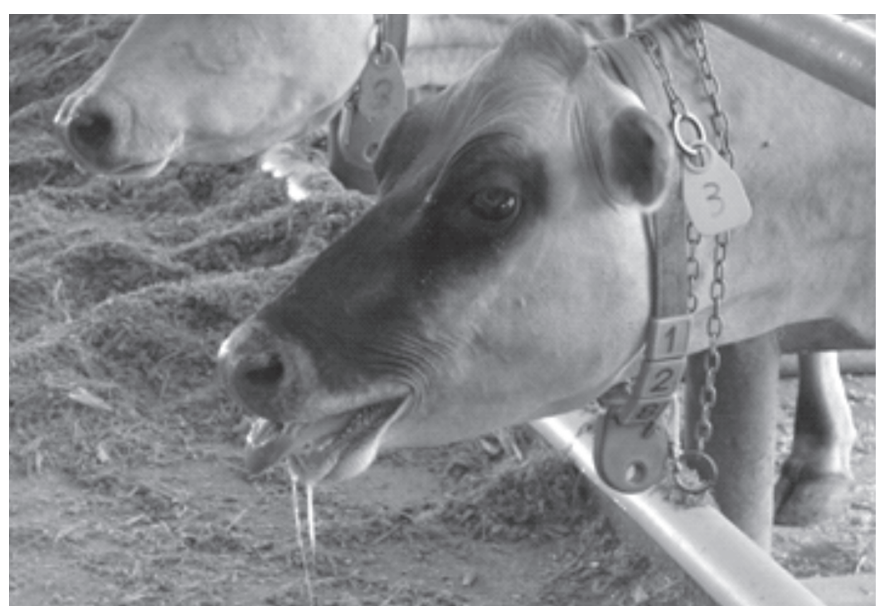


imbalanços nutricionais como o excesso de grãos, a falta de fibra longa da forragem e o manejo alimentar inadequado.

Dantzer (1986) propôs que as estereotipias seriam uma ação compensatória uma vez que, movimentos repetitivos em um ambiente "empobrecido", gerariam estímulos sensórios, dissipariam tensões e "frustações" oriundas do convívio nesse ambiente.

Estudos quantitativos demonstraram que as estereotipias ocorrem quando há uma redução da diversidade de repertórios comportamentais e um decréscimo do número de atos diferentes em um determinado comportamento (Stolba et al. 1983). Por exemplo: porcas criadas soltas na natureza exibem mais de 100 padrões comportamentais distintos e cada um com muitos passos para serem realizados. Porém, quando confinadas o número de atividades comportamentais cai para menos de 30 e passam a ser, cada uma, com menos tarefas para serem realizadas (Stolba et al. 1983).

O empobrecimento ambiental é caracterizado pela redução das oportunidades de realizar, de forma rotineira e natural, as distintas atividades diárias consideradas como normais para os animais. Seu antônimo, o enriquecimento ambiental é sinônimo de aumento de complexidade, que acarreta no desenvolvimento da flexibilidade comportamental em resposta a ambientes dinâmicos, possibilitando uma melhoria da funcionalidade biológica dos animais (Newberry 1995). 0 enriquecimento ambiental atua diretamente na redução de condição emocional negativa (Jones e Waddington 1992, Pearce \& Paterson 1993). A redução de comportamentos considerados anormais e o aparecimento de desempenhos típicos da espécie, têm se mostrado como indicadores da eficácia das técnicas utilizadas para melhorar o enriquecimento ambiental (Newberry 1995).
O curioso hábito de "brincar com a língua ou lingueteio" (tongue-playing) é a estereotipia vista com mais frequência nos ruminantes (Redbo 1990; Redbo \& Nordblad 1997; Mareková et al. 2008). No Brasil, na década de 50, esse comportamento foi encontrado em vários rebanhos leiteiros criados de forma semi-intensiva no Ceará (Canella 2011). Os animais afetados costumam ficar boa parte do tempo jogando sinuosamente a língua para fora da boca ou, às vezes, abrem a boca e ficam enrolando a língua dentro da cavidade oral (Barbosa, comunicação pessoal 2010, Fig.4; Canella 2011).

Sua origem, ainda que desconhecida, provavelmente devese a efeitos multifatoriais originados pelo empobrecimento ambiental, tais como o confinamento por longos períodos, ausência (zero-grazing) ou pouco tempo gasto pastando, excesso de alimentos finamente moídos e o aleitamento artificial mal feito. Os bovinos evoluíram, por milênios, vivendo em liberdade e utilizando sua língua para sentir e coletar alimentos fibrosos de grande tamanho (Van Soest 1994); dessa forma, a ausência ou o pouco tempo disponibilizado para pastar, a oferta constante da dieta e a ingestão de partículas finamente moídas reduzem as atividades de caminhar livremente, mastigar e ruminar sendo, portanto, motivos geradores de "frustação" nos animais. Já em bezerros lactentes, se grande quantidade de leite for ministrada em uma ou duas mamadas diárias e este for dado em baldes ou em mamadeiras cujo orifício do bico foi alargado com o objetivo de reduzir o tempo gasto para aleitar os animais, um grande volume de leite passará rapidamente pela boca, reduzindo a sensação de permanência desse alimento na cavidade oral e, portanto, esse manejo pode causar um sentimento de "frustação", pois os mamíferos precisam de desenvolver o hábito de sucção quando lactentes.

Fig.4. Sequência da estereotipia de "brincar com a língua" em um mesmo bezerro.
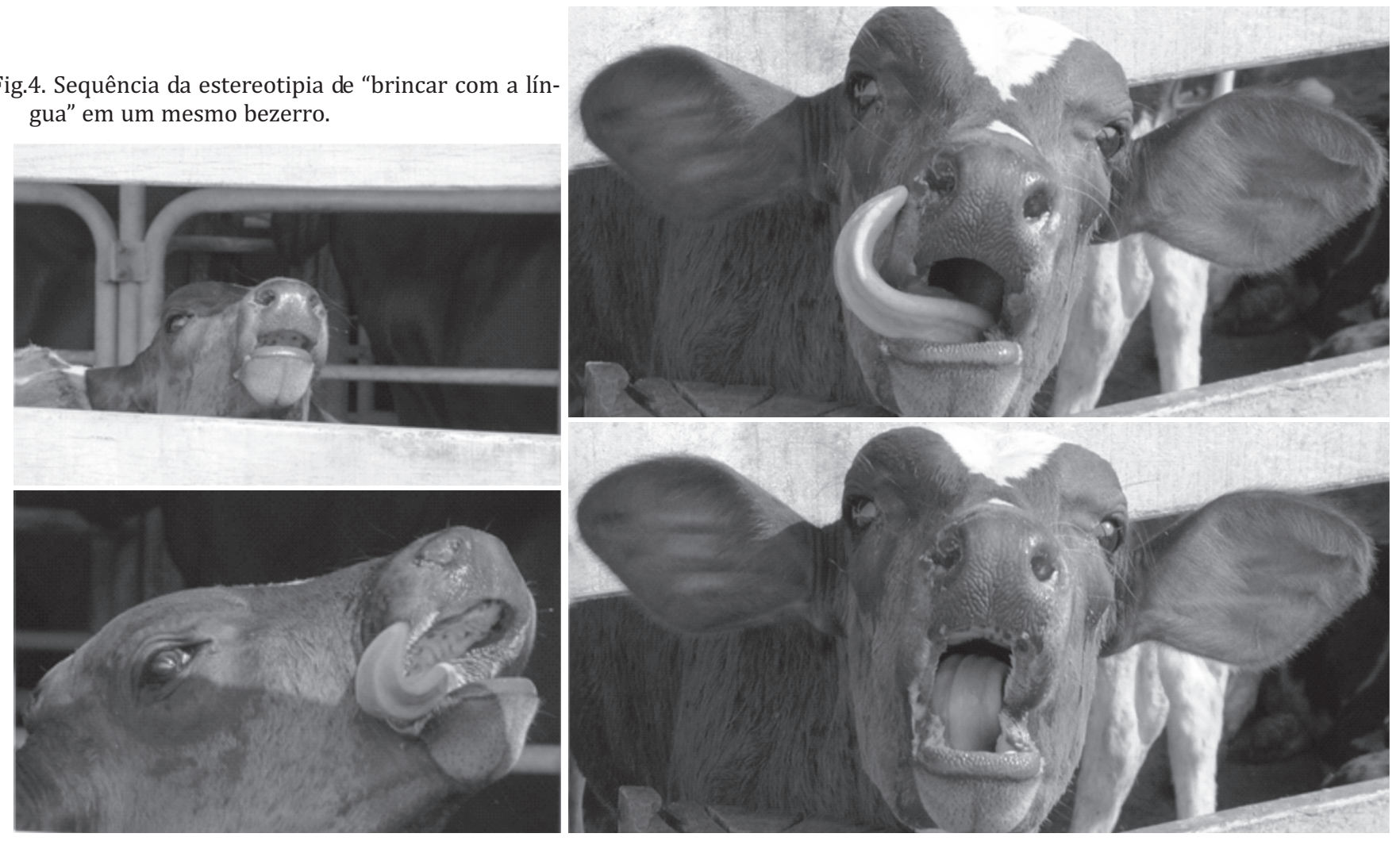
Portanto, a supressão de importantes atividades orais (tempo gasto mastigando, ruminando e mamando) e o empobrecimento ambiental (confinamento, estresse térmico, alta lotação) devem ser os principais agentes desencadeadores da estereotipia de "brincar com a língua". Vale lembrar que esse comportamento estereotipado ainda não foi observado em bovinos criados extensivamente, isto é, em condições de ambiente natural com máxima complexidade exteroceptiva.

\section{Distúrbios comportamentais não estereotipados de na- tureza alimentar}

Decorrentes da deficiência de fibra fisicamente efe-

tiva. Os ruminantes são herbívoros que apareceram no período eoceno, há cerca de 54-34 milhões de anos, e evoluíram, desde então, ingerindo alimentos de origem vegetal (Van Soest 1994, p.31). De acordo com o hábito alimentar, os ruminantes pertencem a três grupos: os animais selecionadores, os intermediários e os pastadores (Hofmann 1989). Os selecionadores sempre preferirão consumir partes dos vegetais pobres em fibra (flores, frutas, brotações e vagens verdes); os pastadores ingerem alimentos ricos em fibra (gramíneas e leguminosas) e os intermediários são aqueles que, de acordo com a oferta, podem consumir alimentos pobres ou não em fibra (Hofmann 1989). Curiosamente ou não, o ser humano domesticou os animais pastadores (bovino, ovino e bubalino) e um intermediário, que foi o caprino.

Mesmo com a ampla variação nas exigências de fibra em sua alimentação, é imperativo saber que os ruminantes são herbívoros, ou seja, necessitam de fibra para fazer funcionar seu sistema digestivo e, conseqüentemente, garantir a sua saúde e bem-estar fisiológicos.

Em relação à fibra, é importante lembrar que se trata de uma entidade nutricional que representa as partes lentamente digeríveis e indigeríveis do alimento e que ocupam espaço no trato gastrintestinal dos animais, além de promover efeitos fisiológicos essenciais à saúde e produtividade animal. Sua análise laboratorial é conhecida como fibra em detergente neutro (FDN), que encerra a celulose, hemicelulose e a lignina (Mertens 1997). A propriedade da fibra que garante a correta estratificação da fase sólida no rúmen, a atividade de ruminação e a manutenção do pH ruminal está contida na FDN fisicamente efetiva (FDNfe), que está associada ao tamanho das partículas fibrosas (Mertens 1997). Assim, para um mesmo alimento volumoso, a FDNfe é máxima quando ele é consumido inteiro e é mínima quando o mesmo for finamente moído.

Portanto, sempre que os volumosos forem moídos e fornecidos com tamanho muito reduzido (p.ex. $<0,5 \mathrm{~cm}$ ), haverá comprometimento nas atividades de ruminação, mastigação e salivação, caracterizando um quadro de deficiência de fibra fisicamente efetiva (tamanho de partículas), mesmo que a dieta seja constituída exclusivamente por forragens. Esta deficiência é agravada quando o volumoso, finamente moído, for de natureza ácida (silagens) e os animais receberem grandes quantidades de concentrados, o que é visto com freqüência nos sistemas intensivos de produção de leite.

Nas situações onde ruminantes são alimentados com dietas onde o tamanho das partículas fibrosas for muito pequeno, eles exibirão um quadro de perversão do apetite, caracterizado por lamberem-se mutuamente (ingerir pêlos), come- rem madeira ou cascas de árvores ou mastigarem cacos de telhas ou pedras (Dirksen 1981, p28). Quando ingeridos, esses "materiais estranhos" atuam como "fibra longa" ou estimulam a salivação durante sua estadia mais prolongada na cavidade oral. Entretanto, é muito importante distinguir essas manifestações oriundas da deficiência de fibra fisicamente efetiva daquela depravação do apetite causada pela deficiência de sódio, que cursa com o ato dos bovinos lamberem-se mutuamente, beberem urina e praticarem geofagia e também da deficiência de cobalto, onde os animais, por exemplo, roem cascas de árvores (Tokarnia et al. 2010). A seguir, são relatados alguns exemplos de alterações no comportamento de ruminantes derivada da falta de estrutura física da dieta.

$\mathrm{O}$ dono de uma caprinocultura, queixando-se de que seus animais estavam com desempenho aquém do esperado, resolveu aumentar o fornecimento diário de concentrado (60\% fubá $+15 \%$ farelo de trigo $+24,5 \%$ farelo de soja $+0,5 \%$ de cloreto de sódio) para 0,5-0,6kg/cabeça/dia e ofertar um capim-elefante (Pennisetum purpureum) "mais novo" e finamente moído para assim melhorar o ganho de peso dos animais a serem comercializados para o corte. A propriedade também utilizava sal mineral, específico para caprinos, nos saleiros dentro das baias. A lotação nessas baias era, em média, 1 animal $/ \mathrm{m}^{2}$ (Malafaia, dados não publicados 2006). Segundo as informações do dono, decorrido um período de aproximadamente dois meses, os animais passaram a exibir uma notória predileção para roer insistentemente a parede das baias (Fig.5); alguns animais mais agoniados até lesionavam a gengiva ao ponto desta sangrar com profusão. Após ser feito o histórico do caso, suspeitou-se que pudesse se tratar da falta de fibra fisicamente efetiva, uma vez que o capim ofertado era realmente "novo" (cerca de 40-45 dias de rebrota, continha $21,3 \%$ de MS e $10,4 \%$ de PB e $67 \%$ de FDN) e demasiadamente moído $(<0,5 \mathrm{~cm})$ e o concentrado era também finamente moído (cerca de $2 \mathrm{~mm}$ ). A suspeita foi confirmada quando os animais foram reduzindo o tempo gasto roendo a baia a partir da oferta do volumoso picado grosseiramente (2$3 \mathrm{~cm}$ ) e da moagem mais grosseira do grão de milho ( $4 \mathrm{~mm})$, até abandonarem esse hábito por completo cerca de 30-40 dias após a alteração na granulometria da dieta e do início da prática de soltá-los 1 a 2 horas/dia em um piquete de capim-mombaça (Panicum maximum cv. mombaça) ao redor da caprinocultura (Malafaia, dados não publicados 2006).

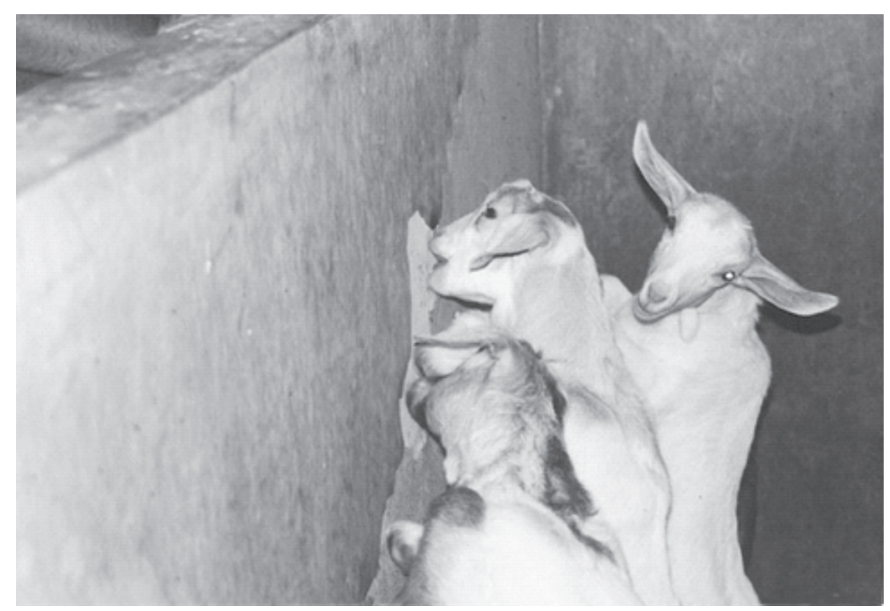

Fig.5. Caprinos jovens, não lactentes, roendo a parede da baia. 
Noutra ocasião, com o objetivo de testar a viabilidade da produção de vitelos caprinos da raça Saanen, um caprinocultor confinou alguns machos recém-nascidos e passou a alimentá-los exclusivamente com leite de vaca fornecido em quantidade crescente a cada semana. Decorridos cerca de 5055 dias, houve uma previsão da meteorologia que uma frente fria passaria pela região e que a temperatura noturna poderia atingir $2-5^{\circ} \mathrm{C}$. Mediante essa previsão, o proprietário resolveu por uma lona plástica preta na única lateral da baia que era feita de ripas de madeira espaçadas a cada $5 \mathrm{~cm}$; após a fixação da lona, os animais praticamente a devoraram em poucos dias, sendo que vários morreram por obstrução abomasal, demonstrando claramente que essa perversão do apetite se deveu à imperativa necessidade de fibra pelos animais (Fig.6). (Malafaia, dados não publicados 2005)

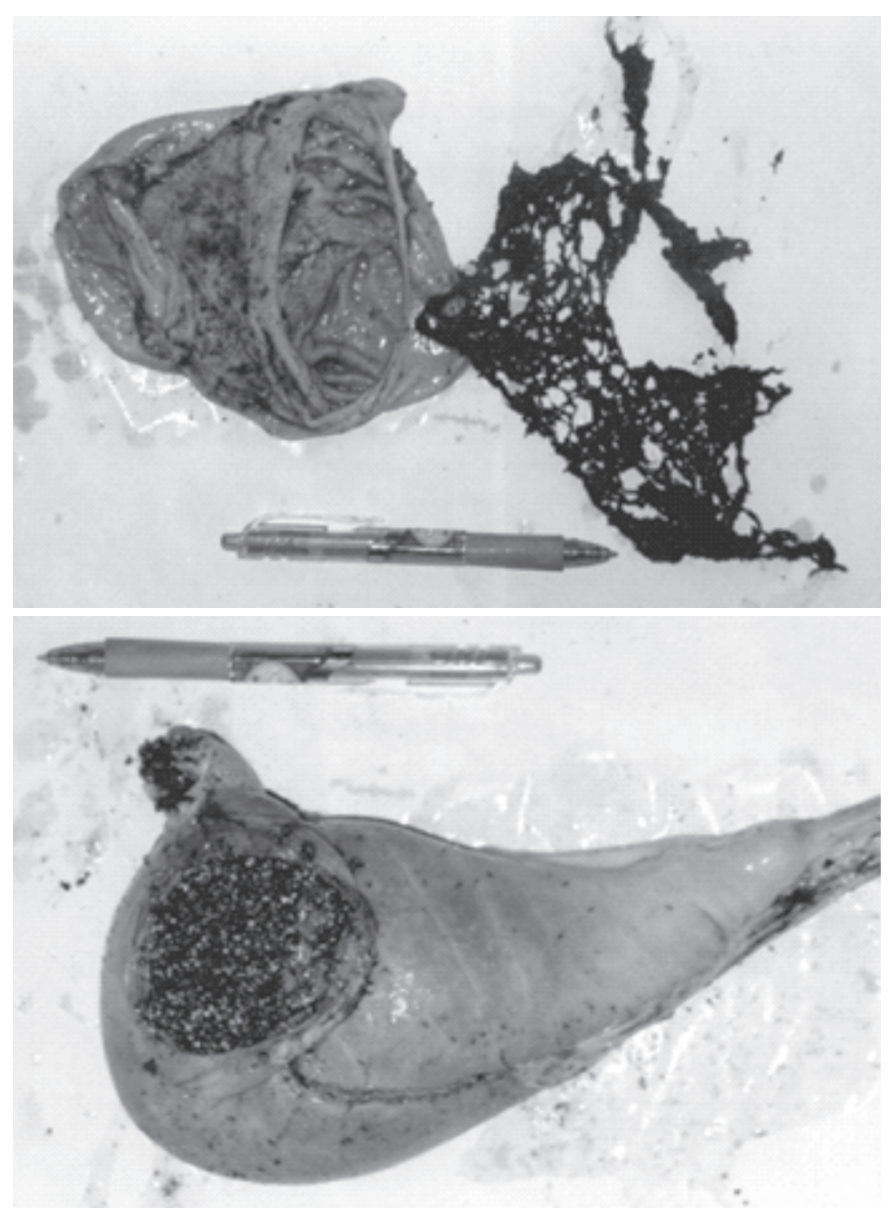

Fig.6. Plástico no abomaso de vitelos com 62 dias de vida.

Recentemente, em função da época seca, um produtor de leite precisou alojar oito bezerras mestiças (100-150kg) em um piquete de aproximadamente $2600 \mathrm{~m}^{2}$, formado por Tifton-85 (Cynodon dactylon cv. Tifton-85) e suplementá-las com silagem de capim-elefante (P. purpureum) feita com cerca de $10 \%$ de fubá. Em um primeiro momento, os animais iniciaram o pastejo e, após superpastejarem toda a área, o pecuarista teve que elevar a oferta diária da silagem até que esta se tornasse, juntamente com $2 \mathrm{~kg}$ de um concentrado, o único alimento volumoso dos animais. Com o decorrer do tempo ( \pm 2 meses) as bezerras, mesmo sendo adequadamen- te suplementadas com cobalto $\left(60 \mathrm{~g}\right.$ de $\mathrm{CoSO}_{4}$ em $100 \mathrm{~kg}$ de cloreto de sódio) passaram a roer insistentemente as árvores que existiam no piquete (Fig. 7). Pensando em provável deficiência de cobalto, resolveu-se elevar a quantidade de $\mathrm{CoSO}_{4}$ para $120 \mathrm{~g} / 100 \mathrm{~kg}$ de $\mathrm{NaCl}$ e os animais continuaram a roer as árvores. Avaliando-se detalhadamente o restante do rebanho (vacas em lactação, vacas secas e garrotes), que permanecia nas pastagens e que recebia o suplemento contendo $60 \mathrm{~g}$ de $\mathrm{CoSO}_{4} / 100 \mathrm{~kg}$ de $\mathrm{NaCl}$, percebeu-se que nenhum animal roia árvores e que estavam com adequado escore corporal e as vacas estavam reproduzindo-se bem (1,5 serviços/ concepção). De sorte que o problema era focalizado apenas no tal piquete onde as bezerras estavam sendo criadas. Contrariando os sinais da deficiência de cobalto, que cursa com notória inapetência, emagrecimento progressivo e o hábito de roer cascas de árvores (Tokarnia et al. 2010), as bezerras estavam consumindo a silagem e o concentrado de forma vigorosa e ganhando peso. De tal forma que o hábito de roer as cascas das árvores foi associado à deficiência de fibra fisicamente efetiva, uma vez que a silagem de capim elefante também era finamente moída $(<1 \mathrm{~cm})$. Quando o proprietário passou a fornecer um pouco de cana-de-açúcar, picada grosseiramente, juntamente com a silagem, os animais foram deixando o hábito de roerem as cascas das árvores e, finalmente, por ocasião da época chuvosa em que foram novamente soltas nos demais pastos da fazenda, abandonaram completamente esse hábito (Malafaia, dados não publicados 2010).

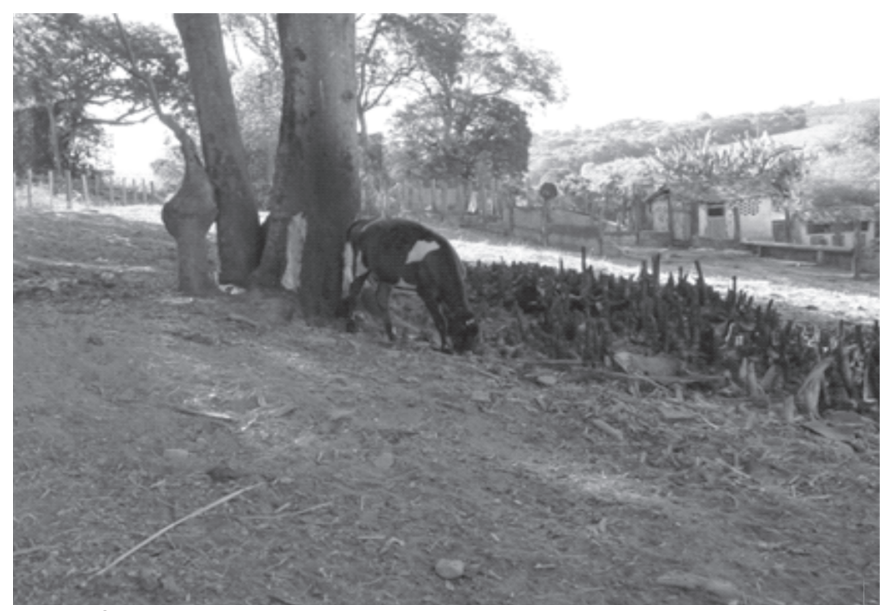

Fig.7. Árvore roída e pasto rapado.

Decorrentes do sistema de aleitamento. Um desvio comportamental freqüentemente observado é o hábito de mastigar e/ou sugar madeira, trincos, cadeados ou canos de ferro (Fig.8a,b) utilizados para a construção dos abrigos onde os bezerros são criados, isoladamente ou não, em sistemas de aleitamento artificial e aleitados duas vezes por dia. Entretanto, é necessário identificar se esse hábito é persistente ao longo do dia, de forma repetitiva, regular ou invariável, o que caracterizaria uma estereotipia. Na maioria das vezes esse hábito é um comportamento não estereotipado resultante da rápida ingestão de um grande volume de leite (fornecido em baldes ou em mamadeiras cujo bico teve seu orifício alargado) e da visualização do tratador ainda fornecendo leite aos demais bezerros (Fig.8b). Neste caso, esse hábito tende a ces- 
sar pouco tempo depois do aleitamento. De Passilé et al. (1992) verificaram que é normal os bezerros, após o aleitamento artificial, realizarem as seguintes atividades: chuparem ou mastigarem objetos presentes nos abrigos, explorarem o interior do abrigo e, por fim, descansarem.
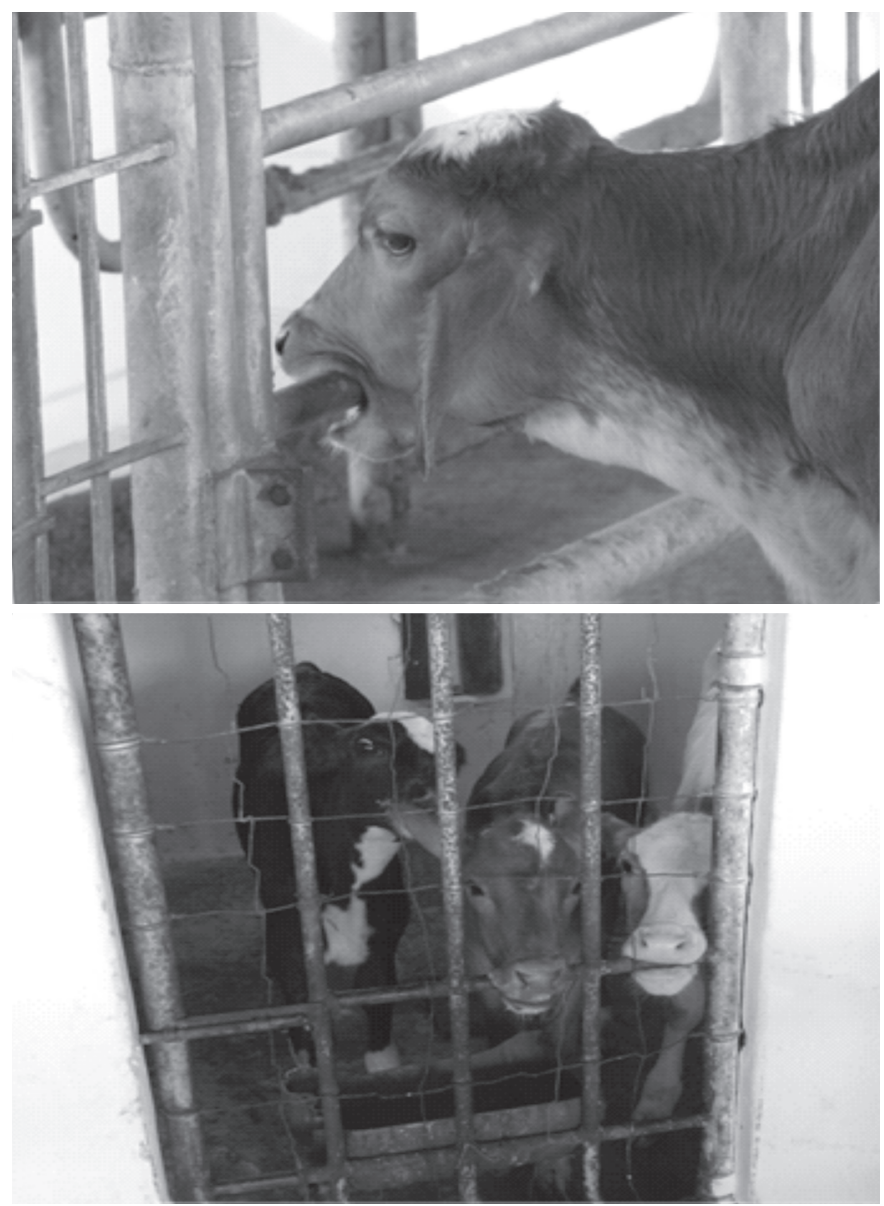

Fig.8. (A) Animal mordendo cano. (B) Duas bezerras mordendo cano e uma chupando a orelha de outra após receberem 2 litros de leite via balde.

Bezerros lactentes (Fig.9) criados coletivamente desenvolvem o comportamento de chuparem ou mamarem avidamente partes de outros animais (orelhas, tetas, bolsa escrotal, prepúcio, umbigo). Ao que parece, esse hábito (cross-sucking) não é uma estereotipia e trata-se de um comportamento anormal oriundo de erros de manejo alimentar em que os animais são aleitados soltos dentro do bezerreiro, ao mesmo tempo e da rápida ingestão de um grande volume de leite em curto espaço de tempo. Sato \& Wood-Gush (1988) verificaram que os bezerros, quando criados com suas respectivas mães, gastam $10-30 \%$ do tempo realizando atividades orais (lamber ou mordiscar objetos sólidos e sucção constante de pequenas quantidades de leite ao longo do dia); esse comportamento, juntamente com o hábito de "imitar" os mais velhos, serve para a inicialização do pastejo, que dará início, por sua vez, à atividade ruminatória. Tudo indica que a minimização das atividades orais, traduzida pela redução do tempo de sucção (causada pela rápida ingestão do leite via balde ou mamadeira) e a competição por leite (oriunda da criação coletiva) se- jam os principais fatores que desencadeiam o cross-sucking nos bezerros. Esse comportamento pode permanecer ativo mesmo após a desmama, quando os animais se sentem "frustados" ao esperar o fornecimento de concentrados (Fig.10). 0 grande problema é que esse hábito pode resultar em danos ao úbere (Fig.11), mamite imediatamente ao primeiro parto e descarte antecipado dos animais que sofrem cross-sucking. Nos casos mais extremáticos alguns animais mamam em si mesmos e nos demais companheiros do rebanho (Fig.12).

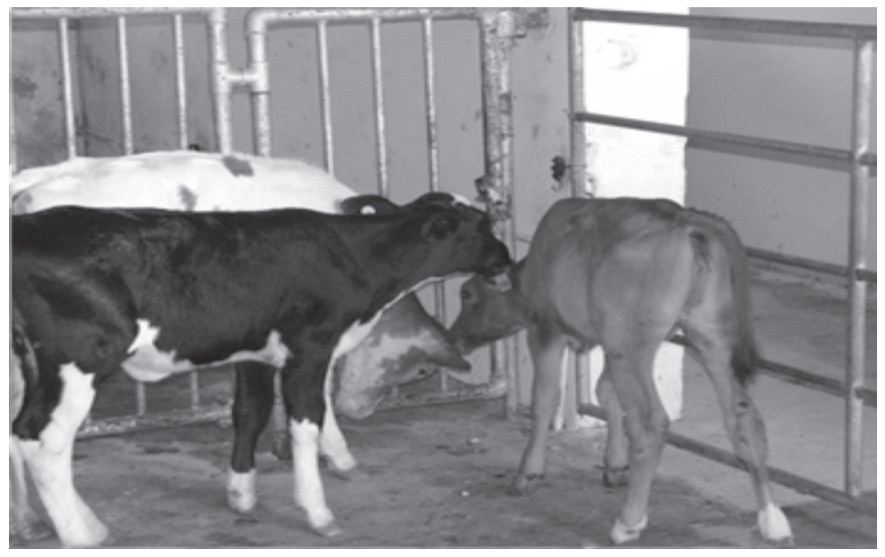

Fig.9. Três bezerras lactentes fazendo cross-sucking.

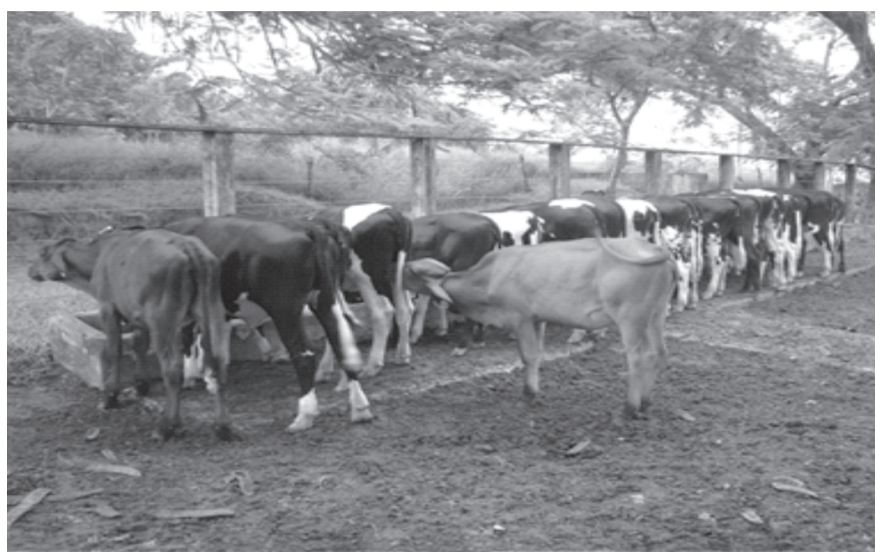

Fig.10. Bezerra desmamada mamando em outra enquanto o lote ingere o arraçoamento matinal.

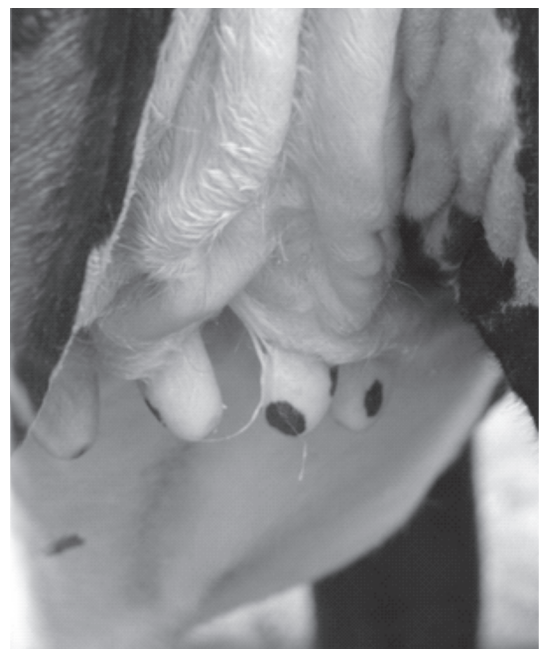

Fig.11. Úbere do animal que sofreu cross-sucking na Figura 10. 


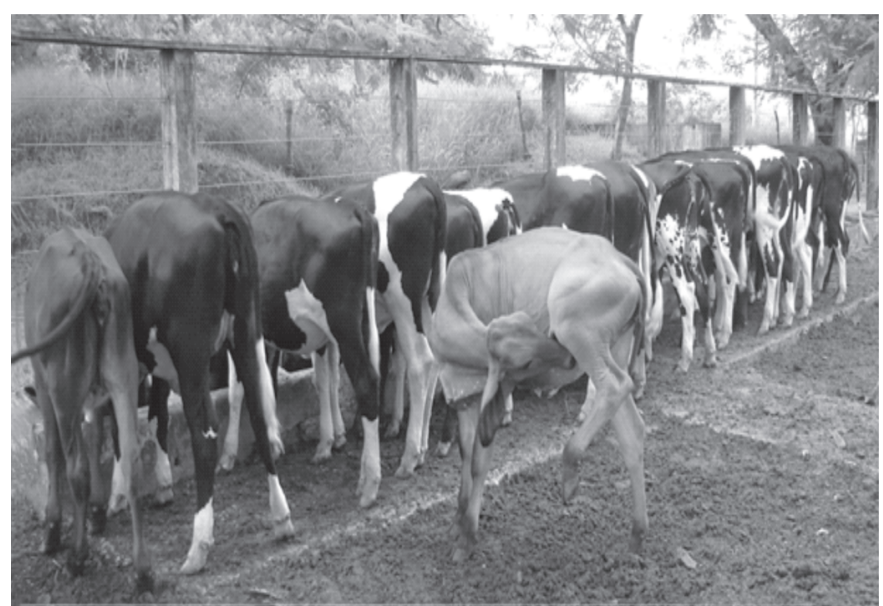

Fig.12. Enquanto todos os animais comem o concentrado a bezerra, habituada a fazer cross-sucking nas outras, começa a mamar em si própria.

As formas, ainda que empíricas, de minimizar o crosssucking nos bezerros seria aleitá-los em separado (amarrálos, distantes uns dos outros, no momento do aleitamento e, após mamarem, deixá-los 10 a 15 minutos presos), evitar ofertar o leite em baldes, dar preferência a sistemas que usem tetas artificiais cujo furo na ponta do bico possui diâmetro reduzido, fornecer um pouco de água (via qualquer sistema com teta artificial), lavar a boca após a ingestão do leite (isso remove o gosto do leite na boca dos animais) e retirar do grupo o animal que porventura apareça com essa alteração, pois especula-se que os animais aprendam, por imitação, a fazer o cross-sucking.

É importante deixar claro que o cross-sucking é um distúrbio comportamental e não é observado em bezerros criados juntos com suas mães no ecossistema das pastagens.

\section{CONCLUSÕES}

Assim como muitas outras espécies mantidas em cativeiro pelo ser humano, os ruminantes também podem exibir uma série de comportamentos incomuns.

É importante que os profissionais que venham a trabalhar com esses animais saibam distinguir se esses hábitos são distúrbios comportamentais originados pelo empobrecimento ambiental, sobretudo quando associado a erros alimentares, que potencializam o quadro de estresse nos animais, ou se são oriundos de doenças ou deficiências nutricionais, que também cursam com transtornos no comportamento animal.

Ao se depararem com um repertório comportamental incomum, os profissionais precisam sempre obter um bom histórico e, no caso de serem comportamentos não associados a doenças ou estados carenciais, devem melhorar as condições de criação provendo enriquecimento ambiental e corrigindo possíveis erros de manejo alimentar.

Agradecimentos.- Ao Professor Ricardo A.M. Vieira (LZNA, Universidade Estadual do Norte Fluminense) pela criteriosa revisão de todo manuscrito e, em especial, nas sugestões e correções conceituais da parte sobre a fibra na nutrição dos ruminantes; ao Professor Carlos Augusto B. Carvalho (Instituto de Zootecnia, UFRRJ) pela correção do texto que versa sobre o animal no ambiente da pastagem; ao Dr. Rogério Magnoli Costa (www.exitorural.com.br) pelas sugestões na parte sobre manejo geral de bovinos de corte; ao Veterinário Camillo F.C. Canella pelas informações concernentes aos casos de estereotipias nos bovinos e ao Zootecnista Paulo H.C. Araújo pela colaboração nos casos de obstrução abomasal em vitelos.

\section{REFERÊNCIAS}

Arave C.W., Albright J.L. \& Sinclair C.L. 1974. Behavior, milking yield, and leukocytes of dairy cows in reduced space and isolation. J. Dairy Sci. 57:1497-1501.

Bennett I.L., Finch V.A. \& Holmes C.R. 1985. Time spent in shade and its relationship with physiological factors of thermoregulation in three breeds of cattle. Appl. Anim. Behav. Sci. 13:227-236.

Broom D.M. \& Johnson K.G. 1993. Stress and animal welfare. Chapman and Hall, London. 211p.

Canella C.F.C. 2011. Comunicação pessoal (Médico Veterinário Autônomo, Vassouras, RJ).

Costa M.J.R.P. \& Costa e Silva E.V. 2007. Aspectos básicos do comportamento social de bovinos. Revta Bras. Reprod. Anim. 31:172-176.

Czako J. 1983. Control of large-scale dairy units ethological view. Proc. $5^{\text {th }}$ World Congress of Animal Production, Amsterdam, Vol.1, p.192-196.

Dantzer R. 1986. Behavioral physiological and functional aspects of stereotyped behavior: A review and a re-interpretation. J. Anim. Sci. 62:1776-1786.

De Passillé A.M.B., Metz J.H.M., Mekking P. \& Wiepkema P.R. 1992. Does drinking milk stimulate suckling in young calves? Appl. Anim. Behav. Sci. 34:23-36.

Dirksen G. 1981. Indigestiones en el bovino. Schnetztor-Verlag GmbH, Konstanz. 79p.

Fraser D., Weary D.M. Pajor E.A. \& Milligan B.N. 1997. A scientific conception of animal welfare that reflects ethical concerns. Anim. Welf. 6:187-205.

Gangwar P.C. 1988. Environmental control as a means of improving animal productivity in tropics. Indian J. Anim. Sci. 58:487-497.

Hindhede J., Mogensen L. \& Sorensen J.T. 1999. Effect of group composition and feeding system on behaviour, production and health of dairy heifers in deep bedding systems. Agric. Scand. Section A, Animal Sci., 49:211-220.

Hofmann R.R. 1989. Evolutionary steps of ecophysiological adaptation and diversification of ruminants: a comparative view of their digestive system. Oecologia 78:443-457.

Hurnik J.F. 1982. Social stress; an often overlooked problem in dairy cattle. Hoard's Dairyman 127:739.

Ítavo L.C.V., Dias A.M., Ítavo C.C.B.F., Euclides Filho K., Morais M.G., Silva F.F., Gomes R.C. \& Silva J.P.B. 2008. Desempenho produtivo, características de carcaça e avaliação econômica de bovinos cruzados, castrados e nãocastrados, terminados em pastagens de Brachiaria decumbens. Arq. Bras. Med. Vet. Zootec. 60:1157-1165.

Jones R.B. \& Waddington D. 1992. Modification of fear in domestic chicks, Gallus gallus domesticus, via regular handling and early environmental enrichment. Anim. Behav. 43:1021-1033.

Kiley-Worthington M. 1977. Behavioural problems of farm animals. Oriel Press, Stocksfield, Engl. 211p.

Kondo S., Maruguchi H. \& Nishino S. 1984. Spatial and social behavior of calves in reduced dry-lot space. Jpn. J. Zootech. Sci. 55:71-77.

Magnoli Costa R. 2011. Comunicação pessoal (Zootecnista, Araçatuba, SP, <www.exitorural.com.br>).

Malafaia P., Cabral. L.S., Vieira R.A.M., Costa R.M. \& Carvalho C.A.B. 2003. Suplementação protéico-energética para bovinos criados em pastagens: aspectos teóricos e principais resultados publicados no Brasil. Livest. Res. f. Rural Development 15:(12) 2003.

Mareková J., Kottferová J., Jakuba T., Ondrasovicova O. \& Ondrasovic M. 2008. Orosthenic syndrome in adult cattle: A minireview. Folia Veterinaria. 52: 75-76.

Mertens D.R. 1997. Creating a system for meeting the fiber requirements of dairy cows. J. Dairy Sci. 80:1463-1481. 
Newberry R.C. 1995. Environmental enrichment - increasing the biological relevance of captive environments. Appl. Anim. Behav. Sci. 44:229-243.

Pearce G.P. \& Paterson A.M. 1993. The effect of space restriction and provision of toys during rearing on the behaviour, productivity, and physiology of males pigs. Appl. Anim. Behav. Sci. 36:11-28.

Peixoto P.V., Malafaia P., Barbosa J.D. \& Tokarnia C.H. 2005. Princípios sobre suplementação mineral e a sanidade de ruminantes. Pesq. Vet. Bras. 25(3):195-200.

Redbo I. 1990. Changes in duration and frequency of stereotypies and their adjoining behaviours in heifers, before, during and after the grazing period. Appl. Anim. Behav. Sci. 26:57-67.

Redbo I. \& Norbland A. 1997. Stereotypies in heifers are affected by feeding regime. Appl. Anim. Behav. Sci. 53: 193-202.

Sato S. \& Wood-Gush D.G.M. 1988. The development of behaviour in beef suckler calves. Biol. Behav. 13:126-142.

Sambraus H.H. 1985. Mouth-based anomalous syndromes, p.391-422. In: Fraser A.F. (Ed.), Ethology of Farm Animals. Elsevier, Amsterdam.
Schake L.M. \& Riggs J.K. 1970. Activities of beef calves reared in confinement. J. Anim. Sci. 31:414-416.

Stafford-Smith D.M., Noble I.R. \& Jones G.K. 1985. A heat balance model for sheep and its use to predict shade seeking behaviour in hot conditions. J. Appl. Ecol. 22:753-774.

Stolba A., Baker N. \& Wood-Gush D.G.M. 1983. The characterization of stereotyped behaviour in stalled sows by informational redundancy. Behaviour 87:157.

Syme G.J. \& Syme L.A. 1979. Social structure in farm animals. Elsevier, Amsterdam. 200p.

Tokarnia C.H., Peixoto P.V., Barbosa J.D., Brito M.F. \& Döbereiner J. 2010. Deficiências Minerais em Animais de Produção. Editora Helianthus, Rio de Janeiro. 191p.

Tokarnia C.H. 2007. Dados não publicados (UFRRJ, Seropédia, RJ).

Van Soest P.J. 1994. Nutritional Ecology of the Ruminants. $2^{\text {nd }}$ ed. Cornell University Press, New York. 476p. 